\title{
Effects of Bethanechol and Adreno- Blockers on Thermoregulation in Spinal Cord Injury
}

\author{
E. J. J. Berard, MD, M. H. Boucand, MD, J. Depassio, MD, J. P. Fyon, \\ MD \\ Spinal Cord Injury Unit, Rehabilitation Service, Hopital Renée Sabran, F 83406 \\ Giens-Hyeres, France.
}

\section{Summary}

The authors report two cases of hypothermia due to a treatment associating Bethanechol and Adreno-Blockers. They emphasise the mechanisms of thermoregulation and discuss the pathophysiology of such hypothermia incidents. The most evident explanation is heat loss, principally mediated through Bethanechol, whereas mechanisms of heat preservation are prevented by Adreno-Blockers.

Patients susceptible to this risk must be carefully monitored.

Keywords: SpinalCordInjury; Thermoregulation; Bathanechol; Adreno-Blockers.

Thermoregulation remains a problem in Spinal Cord Injury, especially when the lesion is above T6 (Massonnet et al., 1977; Guttmann, 1979). In the South of France, tetraplegics often face hyperthermia during summer. Hypothermia is to be expected during winter by tetraplegics who do not wear adequate warm clothing. The autonomic nervous system is responsible for thermoregulation in humans. It acts in different ways, involving both adrenergic and cholinergic transmitters.

During the period of spinal shock, autonomic paralysis prevents spinal cord injured patients from making appropriate adaptations of vasomotor and thermoregulatory responses (Tsai et al., 1980). Besides this initial period of autonomic paralysis, other factors can lead to a dysbalance of normal homeothermia: drugs which mimic or block autonomic transmitters (Depassio et al., 1984). We present here two cases of iatrogenic hypothermia concerning spinal cord injured patients treated with both Bethanechol and Adrenergic-Blockers for lower urinary tract dysfunctioning.

\section{Bethanechol (Urecholine USA,F; Myotonine GB)}

This is a parasympathomimetic, parasympatho-urimetric. Its effects have been tested in vitro on dog bladder muscle contractility (Lipshultz et al., 1973), in 
vivo on isolated rabbit detrusor muscles (Patton et al., 1968) and human urethra. Bethanechol stimulates bladder smooth muscle electrical response (Kaplan et al., 1978).

One can observe its cholinergic muscarinic properties in man, after subcutaneous injection of $1 \mathrm{mg} / 10 \mathrm{~kg}$ Urecholine: there is hypersalivation, flushing, and sweating. These symptoms disappear after injection of an anti-muscarinic such as Methantheline Bromide.

Two Adrenergic Blockers were used in this study: Dibenyline (Phenoxybenzamine), the main pharmacological properties of which are well known, and Alfuzosin. Alfuzosin is a new adrenoblocker derived from dimethoxy-6,7 amino-4 quinazolin, which has anti-hypertensive and vasodilatory properties. It is a selective antagonist of post-synaptic receptors. Its properties have already been demonstrated in animals and healthy volunteers (Cavero et al., 1984), and has been extensively tested in human neurogenic urethral hypertonia. The product is not yet on the market, but a product licence application has been made in France by L.E.R.S. Synthelabo. The product will be available in i.v. and oral formulations.

\section{Case 1}

A 35-year-old male tetraplegic had sustained a spinal cord injury due to a C6-C7 dislocation. Eleven months after injury the patient had significant spasticity below C8, motor power between grades 1 and 2 below C8, thermo-analgesia below T10 and tactile hypoesthesia from T10 to $S 1$. The heart rate was $65 \mathrm{bpm}$, blood pressure 110/60 and temperature $37^{\circ} \mathrm{C}$.

He received Dibenyline (phenoxybenzamine) for the bladder neck hypertonia on 2 March 1981 (increasing gradually to $50 \mathrm{mg}$ per day).

On 20 March 1981, he received $8 \times 25 \mathrm{mg}$ tablets per day Urecholine (bethanechol) for detrusor hypotonia. He also received Lioresal 10 (baclofen) 6 tablets per day, and Lysanxia (prazepam) 3 tablets per day.

On 3 April 1981 at 10:00, he had a sudden attack of abdominal pain, sweating, hypotension $60 / 30 \mathrm{Hg}$, a heart rate at $40 \mathrm{bpm}$ and a fall in temperature in all four limbs (measured with a skin monitor). There was bilateral areactive myosis. He had a boardlike abdomen. The rectal temperature was $35 \cdot 5^{\circ} \mathrm{C}$. There was no blood in either vomit or stool. Abdominal X-ray showed gastric dilatation and a nasogastric catheter was introduced. There was slight vasodilation and generalised sweating above and below the level of the spinal cord injury. The blood pressure was normal at 15:30 after resuscitation with intravenous therapy, but hypothermia continued: $36^{\circ} \mathrm{C}$ at $15: 30,36 \cdot 7^{\circ} \mathrm{C}$ at $21: 00$, $37^{\circ} \mathrm{C}$ at $01: 00,37 \cdot 8^{\circ} \mathrm{C}$ at $08: 00$ on 4 April $36.9^{\circ} \mathrm{C}$ at $12: 00,37 \cdot 7^{\circ} \mathrm{C}$ at 13:00. The heart rate presented the same evolution: $58 \mathrm{bpm}$ at 15:30, 72 at 21:00, 64 at 01:00 on 4 April. Urinary output was normal after resuscitation ( $800 \mathrm{cc}$ within 8 hours).

Abdominal symptoms disappeared and the patient was very well 4 days after this incident.

\section{Case 2}

A 22-year-old male had sustained a spinal cord injury on 4 October 1983 due to a fracture of T3, T4. He had a complete sensory motor paraplegia below T5 with minor spasticity. Urethral venereal disease was treated by cryotherapy. There was urinary retention due to hypertonia of the bladder neck, which prevented its opening. Cystomanometry showed an ineffective voiding pressure of the bladder. $0.7 \mathrm{ml}$ of subcutaneous Urecholine (bethanechol) produced a higher bladder pressure, $50 \mathrm{~cm} \mathrm{H} 20,5$ minutes after infusion. The EMG of the urethral striated sphincter showed signs of spasticity. 
On 15 January 1984 he received Neosynephrine (50 drops per day), Dihydroergotamine (150 drops per day), Calciparine. Before beginning this treatment with Urecholine (bethanechol) and an adrenergic blocker, we noted hepatic insufficiency at the biological study.

On 17 January 1984 the patient received 2 tablets of Acetylcholine, 150 drops of $\mathrm{Di}$ Hydro Ergotamine, 50 drops of Neosynephrine, and $3 \mathrm{mg}$ of Alfuzosin subcutaneously. About 2 hours afterwards the patient felt cold and was vague with generalised sweating. As in case 1 , there was slight vasodilation. The rectal hypothermia was $35.5^{\circ} \mathrm{C}$, the heart rate $90 \mathrm{bpm}$ and the blood pressure $120 / 70 \mathrm{~mm} \mathrm{Hg}$. On 19 January 1984 he received $6 \mathrm{mg}$ Alfuzosin, 4 tablets of Acetylcholine, 150 drops of Dihydroergotamine, 150 drops of Neosynephrine, hypothermia $\left(36^{\circ} \mathrm{C}\right)$ reappeared without any adverse signs. This hypothermia continued throughout the period of treatment and stopped on its conclusion. The treatment consisted only of warming the patient. Temperature never dropped blow $36^{\circ} \mathrm{C}$. Hypothermia $\left(36^{\circ} \mathrm{C}\right)$ reappeared after a second test with Bethanechol alone, which proved Bethanechol was responsible for the dysregulatory homeothermia.

\section{Discussion}

It is important to prevent iatrogenic hypothermia in spinal cord injury patients due to any effect of drugs acting on the autonomic nervous system. Physicians and nurses in charge of the spinal cord injured have to establish a monitoring programme: heart rate, blood pressure and body temperature, twice a day, during the whole period of treatment. In a previous paper (Massonnet et al., 1977) we observed a good correlation between oesophagal and rectal temperature. That is why temperature was monitored rectally in both cases of hypothermic incidents. Attention must be paid to other signs such as shivering or feeling cold, vagueness, disorientation and low urinary output, in order to commence symptomatic treatment by warming the patient and giving hot drinks as soon as possible. If necessary, treatment with parasympatholytic drugs such as Atropine may be added.

The hypothermic incidents took place in April and January respectively: at these times, the spinal cord unit was heated and the ambient temperature was approximatively $24^{\circ} \mathrm{C}$. The pathophysiological background of these incidents raises questions about the part played by neurotransmitters in thermoregulation.

\section{Respiratory tract}

This plays a minor part, through evaporation of water. This mechanism does not directly involve adrenal hormones, or acetylcholine.

\section{Endocrine glands}

In spite of the involvement of the thyroid glands in long term thermoregulation, their function does not obviously use neurotransmitters such as adrenal hormones or acetylcholine. On the other hand, the adrenal glands are closely related to the sympathetic nervous system. In circumstances of emergency, they release adrenaline and noradrenaline to combat cardiovascular shock in general, and hypothermia in particular. 


\section{Heart rate}

This is particularly involved through its acceleration, further increasing thermic exchange producing loss in temperature. In Case 1 the cardiovascular shock is prevailing, with a severe bradycardia at $40 \mathrm{bpm}$ which would theoretically decrease heat loss, but is in fact of no value in this patient.

In Case 2, there is a slight tachycardia at $90 \mathrm{bpm}$. This is supposed to increase exchange in heat loss, and then worsen hypothermia. Bethanechol does not seem to have any negative effect in this patient.

\section{Muscles}

Skeletal muscle contractions during shivering are efficacious in producing heat loss. This response is therefore only useful in circumstances of emergency, but not over a long period of time. Shivering is not mediated through cholinergic controlled sympathetic nerves, but by somatic nerves. It cannot therefore be provoked by Bethanechol.

The muscles of the hairs contract during pilo-erection. It is another way of combating hypothermia, but only useful in furry animals. This mechanism, mediated through noradrenaline, will be blocked by adreno blockers and fail, even above the level of the spinal cord injury. In spite of its non-significant usefulness against hypothermia in man, pilo-erection is a symptomatic indication of autonomic nervous system functioning.

\section{Sweating}

This leads to an important loss of heat through evaporation above and below the level of spinal cord injury. This reaction is mediated through the cholinergic controlled sympathetic, and is enhanced by the use of Bethanechol.

\section{Vasomotricity}

Vasodilation mediated through acetylcholine is a way of losing heat by the means of radiation or convection if there is some air disturbance. Bethanechol enhances this other important mechanism of heat loss. Adreno-blockers prevent vasoconstriction which would conserve some heat by decreasing radiation and convection.

From a purely clinical point of view, we suggest that hypothermia, as in Cases 1 and 2, was mainly the result of sweating, with vasodilation playing a minor part. The severity of the hypothermia was the result of the concurrence of both mechanisms.

We note the more important part played by Bethanechol in iatrogenic hypothermia, and particularly as in Case 2, where Bethanechol alone appeared to be responsible for the hypothermia. Alpha-adrenergic drugs are synergic with Bethanechol in producing hypothermia, so that an association of both drugs make the accident more severe and less easily reversible. The progressive loss of heat explains that hypothermia does not appear at the beginning of the treatment and that thermoregulation is suddenly unbalanced after a while. 


\section{Conclusion}

The knowledge of the occurrence of iatrogenic hypothermia in spinal cord injured patients demands the means of prevention and careful monitoring of the patients at risk. Autonomic dysreflexia, and iatrogenic hypothermia can be anticipated in patients with a high level of spinal cord injury above T6. The association of Bethanechol and alpha blockers is responsible for more severe incidents; while Bethanechol alone can lead to this complication. A specific monitoring programme concerning heart rate, blood pressure and temperature, plus other signs such as shivering or feeling cold, vagueness, disorientation, has to be observed. Heat loss must be prevented, particularly with proper clothing and adequate heating following exposure to climatic changes. Finally, if vesicosphincteric dysfunctioning can be treated otherwise, the association of Bethanechol-Alpha Blockers must be avoided.

\section{Acknowledgement}

With acknowledgements to Susan Jais, Michael and Elisabeth Rogers who helped in writing this paper.

\section{References}

Cavaro I, Lefevre-Borg F, Manoury P 1984 Alfuzosin, an antihypertensive agent with alpha-1adrenoceptor antagonist properties. Federation Proceedings 43(3):2627.

Depassio J, MASSONNET B, VinCENT M, et al. 1984 Thermo-régulation des blessés médullaires et thérapeutiques modifiant l'activité neuro-végétative. Actualités en Rééducation (L Simon) Masson Ed, pp 57-63.

Eyssette M, BeraRd E, Girard R 1977 Les troubles de la sudation dans les lésions médullaires: la sudation sous lésionnelle. Annales de Médecine Physique 20:343-345.

GUTTMANN L 1979 Spinal cord injuries-Comprehensive management and research. Blackwell Ed., London, pp 280-304.

KaPLAN PE, NANNINGA JB, LAL S 1978 Urinary bladder smooth muscle electrical activity: response to Atropine and Bethanechol. Archives of Physical Medicine and Rehabilitation 59(5):454.

LiPSHUlTZ LI, ROHNER TJ, CURRY TH, et al., 1973 The effects of Imipramine on in vitro dog bladder muscle contractility. Investigative Urology 11:182-185.

Massonnet B, Charazac M, Bourret J, et al., 1977 Comparison of thermoregulatory heat response in upper and lower part of the body in paraplegic and healthy human. Symposium on temperature regulation. 27th International Congress of Physical Science LILLE (Abstract).

Patton M 1968 Pharmacology of isolated rabbit detrusor muscle. Clinical Research 16:393.

Tsai SH, SHIH CJ, SHYY TT, et al., 1980 Recovery of vaso-motor response in human spinal cord trans-section. Fournal of Neurosurgery 52:808-811. 